1 Programa de Pós-Graduação em Ciências Médicas, Laboratório do Sono e Ritmos Biológicos, Universidade Federal do Ceará (UFC), Fortaleza, CE, Brazil 2 Faculdade de Medicina, UFC, Fortaleza, CE, Brazil
Correspondence to:

Veralice Meireles Sales de Bruin Faculdade de Medicina, Universidade Federal do Ceará Rua Prof. Costa Mendes, 1608 $4^{\circ}$ andar

60430-040 - Fortaleza, CE, Brazil veralice@superig.com.br

Recebido em 5/Mar/2012 Aceito em 4/Out/2012

\section{Associations among physical activity, comorbidities, depressive symptoms and health-related quality of life in type 2 diabetes}

\author{
Associações entre atividade física, comorbidades, sintomas depressivos \\ e qualidade de vida relacionada à saúde em diabéticos tipo 2
}

Thiago Medeiros da Costa Daniele ${ }^{1,2}$, Veralice Meireles Sales de Bruin ${ }^{1,2}$, Débora Siqueira Nobre de Oliveira ${ }^{2}$, Clara Mota Randal Pompeu ${ }^{2}$, Adriana Costa e Forti ${ }^{2}$

\begin{abstract}
Objective: To investigate associations between physical activity, comorbidity severity, depressive symptoms, and health-related quality of life in type 2 diabetes mellitus. Subjects and methods: All individuals, 200 patients and 50 controls, aged from 40 to 60 years, were investigated by interview, and all variables were measured concurrently. Physical activity was evaluated by the International Physical Activity Questionnaire (IPAO), Health-Related Quality of Life (HROL) by the Short-Form Health Survey (SF-36), comorbidity severity by the Charlson Comorbidity Index (CCI), and depressive symptoms by the Beck Depression Inventory (BDI-II $\geq 16$ ). Single and multiple regression analysis evaluated the effects of independent variables on physical activity. Results: The patients had more depressive symptoms and greater comorbidity severity $(p<0.005)$. Diabetic patients showed better activity levels (IPAQ) $(p<0.005)$. Functional Capacity, General State of Health, and Physical Limitation were the most affected subscales in the SF-36 evaluation of the HROL. Sedentary diabetic patients had higher waist circumference, waist-to-hip ratios, more depressive symptoms, and worse HRQL. Functional capacity $(p=0.000)$, followed by General State of Health $(p=0.02)$, were the health status measure subscales independently associated with physical activity. Conclusions: The findings suggest that increasing patient independence and treating depressive symptoms can promote physical activity for type 2 diabetes mellitus patients. It is suggested that group activities and caregivers/family support might compensate for the patient dependence, and increase adherence to exercise programs in those that are less active. Arq Bras Endocrinol Metab. 2013;57(1):44-50
\end{abstract}

Keywords

Type 2 diabetes; physical activity; quality of life; depressive symptoms; functional capacity

\section{RESUMO}

Objetivo: Investigar as associações entre atividade física, gravidade das comorbidades, sintomas depressivos e qualidade de vida relacionada à saúde em pacientes com diabetes mellitus tipo 2 . Sujeitos e métodos: Todos os indivíduos, 200 pacientes e 50 controles, com idades entre 40 e 60 anos, foram analisados por entrevistas, e todas as variáveis foram medidas neste mesmo momento. A atividade física foi avaliada pelo International Physical Activity Questionnaire (IPAQ); a qualidade de vida relacionada à saúde (OVRS), pelo Short-Form Health Survey (SF-36); a gravidade das comorbidades, pelo Índice de Comorbidade de Charlson (CCl); e os sintomas depressivos foram avaliados pelo Inventário de Depressão de Beck (BDI-II $\geq 16)$. A análise de regressão simples e múltipla avaliou os efeitos das variáveis independentes sobre a atividade física. Resultados: Os pacientes apresentaram mais sintomas depressivos e maior gravidade das comorbidades $(p<0,005)$. Os pacientes diabéticos apresentaram melhores níveis de atividade (IPAQ) $(p<0,005)$. A Capacidade Funcional, a Condição Geral de Saúde e a Limitação Física foram as subescalas mais afetadas na avaliação da QVRS no SF-36. Os pacientes diabéticos sedentários apresentaram maior circunferência da cintura, proporção cintura-quadril, mais sintomas depressivos e pior QVRS. A Capacidade Funcional $(p=0,000)$, seguida pela Condição Geral de Saúde $(p=0,02)$, foram as subescalas de medida de condição de saúde associadas independentemente com a atividade física. Conclusões: Os achados sugerem que a independência dos pacientes e o tratamentos dos sintomas depressivos podem promover a atividade física para pacientes com diabetes mellitus tipo 2. Sugere-se que atividades em grupo e o apoio da família/cuidadores podem compensar a dependência do paciente e aumentar a aderência ao programa de exercícios nos pacientes menos ativos.Arq Bras Endocrinol Metab. 2013;57(1):44-50 


\section{INTRODUCTION}

$\mathrm{D}$ iabetes is a chronic disease that affects millions of people and its complications have increasing effects on quality of life and mortality $(1,2)$. The number of people with type 2 diabetes (T2DM) will rise from 135 million in 1995 to 300 million in the year of 2025 (3). Thus, measures to prevent diabetes and metabolic syndrome are vital to reduce the escalating cost of this highly endemic disorder. Many complications associated with diabetes, such as hypertension, stroke, impaired mental health, muscular weakness, depression, and diurnal somnolence have also been linked to sedentary life $(4,5)$. Moreover, it has been largely demonstrated that lifestyle interventions that include regular physical activity and healthier dietary habits are beneficial for diabetic patients $(6,7)$.

Lower basal levels of PA have been associated with poor mental health (8), depression and perceived stress (9-11). Lifestyle intervention programs for T2DM have been previously verified in many controlled trials: PA shows better effects on glycemic control and blood pressure than other therapies alone $(12,13)$. Resistance training (14), isolated aerobic exercise, (15) and the combination of them (16) can improve glycemic adjustments; overall, the beneficial effects of exercise on physical fitness, disease symptoms, and quality of life in T2DM are strong (17-21). However, despite all these evidences, most patients remain sedentary $(22,23)$.

Most lifestyle intervention studies have focused on education programs (24), including advice on PA (25), $\operatorname{diet}(26)$, and both (19). An Italian study reported that behavioral changes are needed to achieve the goals of exercise training: in this study, lack of time and negative attitudes were the most common obstacles reported by patients (27). In fact, increasing awareness of patients and physicians about the benefits of PA on reducing obesity, insulin resistance, and cardiovascular complications has already been done. Given that, and despite frequent physicians recommendation of a physically active lifestyle, patient adherence is still low. It needs to be strengthened by the investigation of factors influencing adherence to physical activity, which can possibly lead to measures for improvement exercise programs effectiveness (28).

The Diabetes and Physical Activity in Fortaleza (DPAF) study is a clinical study that explores the status of PA and fitness in individuals with T2DM. The objec- tives of this study were: first, to evaluate the level of PA and health related quality of life in T2DM patients and second, to examine the associated factors.

\section{SUBJECTS AND METHODS}

\section{Study design}

This is an observational cross-sectional analysis of consecutive T2DM patients regularly seen at the Integrated Center for Diabetes and Hypertension (CIDH) in Fortaleza, Brazil (DPAF study). Diagnosis of T2DM was defined according to the criteria of the American Diabetes Association (29). The study involved patients aged from 40 to 60 years old, consecutively recruited over a period of 12 months (November, 2010 to October, 2011). A subsample of 200 patients agreed to participate in this study and were interviewed. The $\mathrm{CIDH}$ provides treatment to approximately 5,000 diabetic patients per month. Initially, 324 patients were examined and 124 patients were excluded: 75 individuals refused to participate, 19 were diagnosed with diabetes mellitus type 1 , five had recent hospitalization, two were pregnant, and 20 individuals were out of age range of the inclusion criteria. Controls were healthy subjects selected among staff personnel. In this study of diabetic patients, we avoided recruiting family members due to the possibility of a family link. Also, the reduced number of control subjects was due to the strict exclusion criteria associated comorbidities, such as arterial hypertension, diabetes and familial diabetes, among others. The specific questionnaires were all done concurrently in a face to face interview by two professionals from the medical staff. Patients were excluded if they had severe associated comorbid disorder, recent hospitalization, and were not competent to give informed consent. The study protocol was approved by the local Research Ethics Committee (CEP 031-04-09), and written informed consent was obtained in all cases.

\section{Outcome measures}

Demographic data, habits, and comorbidities were recorded using a standardized questionnaire. Measurement of physical activity was done using the International Physical Activity Questionnaire (IPAQ) that estimates the habitual level of physical activity (30), and whose reliability has been previously proven in the evaluation of physical activity levels in Lat- 
in America (31). IPAQ has three levels of physical activity: low, moderate, and high. The Health Status Index or Health Related Quality of Life (HRQL) was studied with the Short-Form Health Survey (SF-36) (32). The Sf-36 evaluates quality of life in eight domains related to physical and mental health, and each variable ranges from 0 to 100 points, with zero being the worst and 100 the best possible score. Accuracy, reliability, validity, and adequacy of the HRQL in Brazil has already been proven (33). Comorbidity severity was evaluated with the Charlson Comorbidity Index (CCI); scores range from 0 to 37 , and higher scores indicating worse comorbidity severity (34). This questionnaire has been previously used in a Brazilian population, and its validity was examined (35). Depressive symptoms were evaluated by the Beck Depression Inventory (BDI-II) and were defined as present if the score was greater than $16(36)$. A Brazilian version of the BDI has been previously validated (37). In our study, physical inactivity was defined as less than 30 minutes of exercise per day, and absence of heavy physical exertion at home or work, namely cleaning, hand washing clothes, or others.

\section{Statistical analysis}

Descriptive statistics are presented as mean \pm standard deviation, range and frequency (\% values). Fisher's Exact Test for categorical variables, Mann-Whitney $U$ test for continuous variables, and Student's t test for normally distributed data with equal variances were performed to compare cases and controls. Pearson's correlation coefficients were calculated to evaluate the relationship between measures. A forward stepwise multiple regression analysis evaluated how variables predicted physical activity levels (IPAQ). Initially, all potential variables were analyzed; in the final model, variables with $\mathrm{p}<$ 0.15 were all included as potential predictor variables; a $\mathrm{P}<0.05$ was required for a variable to be retained in the final model. Statistical analysis was carried out using SPSS for Windows, version 16.0. Statistical significance was set at $\mathrm{p}<0.05$.

\section{Results}

Comparisons between patients and control subjects are depicted in table 1 . Two hundred patients with T2DM aged from 40 to $60(52.7 \pm 5.6)$ years old, with $59 \%$ females, were studied. Disease duration oscillated from one to 12 years $(11.7 \pm 7.5)$. Body mass index varied from 17.6 to $49.7 \mathrm{~kg} / \mathrm{m}^{2}(30.0 \pm 5.1)$, waist circumference from 55.6 to $141.0 \mathrm{~cm}(100.3 \pm 12.1)$ and waistto-hip ratio varied from 0.48 to $1.26(0.95 \pm 0.08)$. Body adiposity index ranged from 18.2 to 53.3 (34.4 $\pm 6.7)$. Neck circumference ranged from 23.2 to 54.1 $(38.4 \pm 4.1)$.

Among diabetic patients, $76 \%$ of cases $(\mathrm{N}=133)$ had hypertension. No gender differences were found between cases with and without hypertension $($ Male $=$ $40 \%$ and female $60 \%$, Fisher's Exact test $\mathrm{p}=0.5)$. As expected, hypertension and peripheral neuropathy $(\mathrm{p}<$ $0.005)$ were found more frequently in diabetic patients. Peripheral neuropathy was identified in $63 \%(\mathrm{~N}=109)$ of the patients; no gender differences were found between cases with and without peripheral neuropathy (Male $=38 \%$ and female 62\%, Fisher's Exact test $\mathrm{p}=$ $0.76)$. Coronaropathy was found in $19 \%(\mathrm{~N}=33)$ of the patients; no gender differences were found between cases with and without of coronaropathy (Male $=36 \%$ and female $=64 \%$, Fisher's Exact Test $\mathrm{p}=1.0)$. Previous stroke was identified in $12 \%(\mathrm{~N}=24)$ of the patients, and no gender differences were found (Male $=$ $42 \%$ and female $=58 \%$, Fisher's Exact Test $\mathrm{p}=1.0$ ). Six percent $(\mathrm{N}=10)$ of cases consumed more than 6 cups of coffee/day. Depressive symptoms were present in $53(30 \%)$ subjects, and among these, $39(66 \%)$ were female. Depressive symptoms and comorbidity severity were greater in diabetic patients. Twenty-six patients (11\%) reported ingestion of sleep-inducing medications. Control subjects reported more frequent heavy drinking $(\mathrm{p}=0.001)$. Regarding the SF-36 subscales, Functional Capacity, Physical Limitation, Pain and General State of Health were more affected in diabetic patients. Interestingly, patients were less sedentary than controls (Table 1).

The analysis of cases according to physical activity (IPAQ) showed that the more sedentary patients, the larger the neck circumference, hip-to-waist ratio, and waist circumference. Also, sedentary patients had more depressive symptoms. Regarding, SF-36 subscales, sedentary patients had worse Functional Capacity, Physical Limitation, Pain, General State of Health, and Emotional Limitations (Table 2). Multivariate analysis showed that, among the Health Status Index (SF-36) subscales, Functional Capacity $(\mathrm{p}=0.000)$ and General State of Health $(\mathrm{p}=0.02)$ were independently associated with IPAQ levels (Table 3). 
Table 1. Clinical/demographic data and behavioral scales of type 2 diabetic patients and controls

\begin{tabular}{|c|c|c|c|}
\hline Variables & Type 2 diabetes $(\mathrm{N}=\mathbf{2 0 0})$ & Controls $(\mathrm{N}=50)$ & $P$ value \\
\hline \multicolumn{4}{|l|}{ Clinical and demographic variables } \\
\hline Gender M/F (N/\% values) & $84 / 116(42 \% / 58 \%)$ & $26 / 24(52 \% / 48 \%)$ & ${ }^{\mathrm{a}} 0.20$ \\
\hline Age, yrs, Mean (SD) & $52.7(5.7)$ & $52.2(5.8)$ & b 0.62 \\
\hline Disease duration, yrs, Mean (SD) & $11.7(7.5)$ & NA & - \\
\hline BMI $\left(\mathrm{kg} / \mathrm{cm}^{2}\right)$, Mean (SD) & $30.1(5.4)$ & $28.9(4.8)$ & b 0.15 \\
\hline Body Adiposity Index, Mean (SD) & $34.4(6.7)$ & $32.3(6.6)$ & ${ }^{\mathrm{b}} 0.51$ \\
\hline Neck circumference (cm), Mean (SD) & $38.4(4.1)$ & $37.8(4.5)$ & b 0.39 \\
\hline Waist-to-hip ratio, Mean (SD) & $0.95(0.08)$ & $0.93(0.08)$ & ${ }^{\mathrm{b}} 0.16$ \\
\hline Waist circumference (cm), Mean (SD) & $100.3(12.1)$ & $96.3(14.0)$ & b 0.42 \\
\hline Hypertension N (\%) & $153(76 \%)$ & $18(36 \%)$ & ${ }^{\mathrm{a}} 0.000^{* *}$ \\
\hline Coronaropathy N (\%) & $39(20 \%)$ & $2(4 \%)$ & a $0.05^{*}$ \\
\hline Stroke N (\%) & $24(12 \%)$ & $1(3 \%)$ & a 0.35 \\
\hline Heavy drinking $\mathrm{N}(\%)$ & $20(10 \%)$ & $15(30 \%)$ & ${ }^{\mathrm{a}} 0.001^{* *}$ \\
\hline Peripheral neuropathy N (\%) & $129(65 \%)$ & $4(8 \%)$ & ${ }^{\mathrm{a}} 0.000^{* *}$ \\
\hline \multicolumn{4}{|l|}{ Scales } \\
\hline BDI-II mean (SD) & $10.1(8.4)$ & $5.6(7.0)$ & ${ }^{\mathrm{c}} 0.001^{* *}$ \\
\hline CCI. N (\%) & & & ${ }^{\mathrm{a}} 0.000^{* *}$ \\
\hline$=0$ & $30(15 \%)$ & $38(76 \%)$ & \\
\hline$=1$ & $25(13 \%)$ & $9(18 \%)$ & \\
\hline$\geq 2$ & $145(73 \%)$ & $3(6 \%)$ & \\
\hline \multicolumn{4}{|l|}{ SF-36 domains } \\
\hline Functional capacity & $54.0(31.6)$ & $85.8(17.4)$ & ${ }^{\mathrm{c}} 0.000^{* *}$ \\
\hline Physical limitation & $46.0(44.5)$ & $86.0(29.5)$ & ${ }^{\mathrm{c}} 0.000^{* *}$ \\
\hline Pain & $55.2(30.8)$ & $74.9(25.0)$ & ${ }^{\mathrm{c}} 0.02^{*}$ \\
\hline General state of health & $45.0(22.8)$ & $61.3(17.6)$ & ${ }^{\mathrm{c}} 0.000^{* *}$ \\
\hline Vitality & $60.2(25.5)$ & $69.2(15.7)$ & ${ }^{\mathrm{c}} 0.59$ \\
\hline Social aspects & $70.6(31.0)$ & $84.0(27.4)$ & ${ }^{\mathrm{c}} 0.09$ \\
\hline Emotional limitations & 73.3 (39.8) & $88.6(27.4)$ & ${ }^{\mathrm{c}} 0.17$ \\
\hline Mental health & $67.3(23.8)$ & $73.0(19.0)$ & ${ }^{\mathrm{c}} 0.46$ \\
\hline IPAO domains & & & ${ }^{\mathrm{b}} 0.000^{* *}$ \\
\hline Sedentary N (\%) & $79(40 \%)$ & $36(72 \%)$ & \\
\hline Irregularly active $\mathrm{N}(\%)$ & $65(33 \%)$ & $10(20 \%)$ & \\
\hline Active N (\%) & $40(20 \%)$ & $2(4 \%)$ & \\
\hline Very active $\mathrm{N}(\%)$ & $16(8 \%)$ & $2(4 \%)$ & \\
\hline
\end{tabular}

BMI: body mass index; BDI-II: Beck Depression Inventory; CCI: Charlson Comorbidity Index IPAQ: International Physical Activity Questionnaire; SF-36: Short-Form Health Survey. ${ }^{\mathrm{a}} \chi^{2}$ - square test, ${ }^{\mathrm{b}}$ Students $t$ test; ${ }^{\mathrm{c}}$ Mann Whitney. ${ }^{*} \mathrm{P}<0.05 ;{ }^{*} \mathrm{P}<0.01$.

\section{DISCUSSION}

The main finding of this study is that the Health Status Index (SF-36) subscale Functional Capacity, followed by General State of Health, were associated with the level of physical activity in type 2 diabetic patients. These findings show that functional capacity that main- ly evaluates the degree of patient independence is an important factor determining physical activity. Also, depressive symptoms were worse among more sedentary patients. Theoretically, increasing patient independence either with reassurance or caregiver and/or family support could improve physical activity. In this sense, group 
Table 2. Clinical/demographic characteristics of type 2 diabetic patients according to the levels of physical activity

\begin{tabular}{|c|c|c|c|c|c|}
\hline Variables & $\begin{array}{c}\text { Sedentary } \\
\mathrm{N}=79\end{array}$ & $\begin{array}{l}\text { Irregularly active } \\
\qquad N=65\end{array}$ & $\begin{array}{l}\text { Active } \\
\mathrm{N}=40\end{array}$ & $\begin{array}{c}\text { Very active } \\
N=16\end{array}$ & $P$ value \\
\hline \multicolumn{6}{|l|}{ Clinical and demographic variables } \\
\hline Gender M/F (N/\% values) & $38 / 41(48 \% / 52 \%)$ & $21 / 41(37 \% / 63 \%)$ & $14 / 26(35 \% / 65 \%)$ & $8 / 8(50 \% / 50 \%)$ & a 0.37 \\
\hline Age, yrs, Mean (SD) & $52.8(0.6)$ & $51.8(0.6)$ & $53.1(0.8)$ & $54.0(1.5)$ & ${ }^{\mathrm{b}} 0.72$ \\
\hline Disease duration, yrs, Mean (SD) & $13.3(1.6)$ & $11.7(0.8)$ & $11.9(0.8)$ & $11.3(1.6)$ & ${ }^{\mathrm{b}} 0.75$ \\
\hline BMI $\left(\mathrm{kg} / \mathrm{cm}^{2}\right)$, Mean (SD) & $30.9(0.6)$ & $29.9(0.6)$ & $29.5(0.7)$ & $28.2(1.2)$ & ${ }^{\mathrm{b}} 0.24$ \\
\hline Body Adiposity Index, Mean (SD) & $34.4(0.7)$ & $34.2(0.8)$ & $35.3(1.0)$ & $32.7(1.9)$ & ${ }^{\mathrm{b}} 0.37$ \\
\hline Neck circumference (cm), Mean (SD) & $40.0(0.7)$ & $37.6(0.5)$ & $37.6(0.6)$ & $38.6(0.9)$ & ${ }^{\mathrm{b}} 0.02^{*}$ \\
\hline Waist-to-hip ratio, Mean (SD) & $0.98(0.08)$ & $0.95(0.009)$ & $0.90(0.01)$ & $0.92(0.01)$ & $\mathrm{b} 0.000^{* *}$ \\
\hline Waist circumference (cm), Mean (SD) & $104.2(1.4)$ & $98.8(1.4)$ & $97.1(1.7)$ & $96.4(2.7)$ & ${ }^{\mathrm{b}} 0.003^{*}$ \\
\hline Hypertension N (\%) & $63(80 \%)$ & $49(75 \%)$ & $30(75 \%)$ & $11(69 \%)$ & a 0.77 \\
\hline Coronaropathy N (\%) & $21(27 \%)$ & $11(17 \%)$ & $7(17 \%)$ & $0(0 \%)$ & a 0.07 \\
\hline Stroke N (\%) & $13(16 \%)$ & $7(11 \%)$ & $2(5 \%)$ & $2(12 \%)$ & a 0.32 \\
\hline Heavy drinking N (\%) & $8(10 \%)$ & $7(11 \%)$ & $2(5 \%)$ & $3(19 \%)$ & a 0.47 \\
\hline Peripheral neuropathy N (\%) & $59(75 \%)$ & $37(57 \%)$ & $24(60 \%)$ & $9(56 \%)$ & a 0.11 \\
\hline \multicolumn{6}{|l|}{ Scales } \\
\hline BDI-II mean (SD) & $11.0(0.8)$ & $10.6(1.1)$ & $9.2(1.4)$ & $5.4(1.0)$ & ${ }^{\mathrm{c}} 0.03^{*}$ \\
\hline $\mathrm{CCl}$ & & & & & a 0.69 \\
\hline$=0$ & $10(13 \%)$ & $11(17 \%)$ & $6(15 \%)$ & $3(19 \%)$ & \\
\hline$=1$ & $10(13 \%)$ & $9(14 \%)$ & $3(8 \%)$ & $3(19 \%)$ & \\
\hline$\geq 2$ & $59(74 \%)$ & $45(69 \%)$ & $31(77 \%)$ & $10(62 \%)$ & \\
\hline SF-36 domains & & & & & ${ }^{\circ} 0.000^{* *}$ \\
\hline Functional capacity & $40.5(3.5)$ & $59.1(3.7)$ & $69.6(4.3)$ & $61.2(6.3)$ & ${ }^{\mathrm{c}} 0.005^{* *}$ \\
\hline Physical limitation & $34.8(4.9)$ & $46.9(5.2)$ & $65.6(6.9)$ & $48.4(11.2)$ & ${ }^{\mathrm{c}} 0.03^{*}$ \\
\hline Pain & $50.1(3.5)$ & $52.7(3.4)$ & $67.8(4.9)$ & $59.4(7.9)$ & ${ }^{\mathrm{c}} 0.000^{* *}$ \\
\hline General state of health & $40.2(2.4)$ & $41.0(2.7)$ & 59.5 (3.2) & $48.2(5.9)$ & ${ }^{\mathrm{c}} 0.03^{*}$ \\
\hline Vitality & $54.7(2.8)$ & $58.5(3.2)$ & $71.3(3.8)$ & $65.9(4.5)$ & ${ }^{\mathrm{c}} 0.09$ \\
\hline Social aspects & $67.2(3.5)$ & $68.4(3.6)$ & $76.5(5.2)$ & $82.0(6.7)$ & ${ }^{\mathrm{c}} 0.20$ \\
\hline Emotional limitations & $67.6(4.8)$ & $72.8(4.8)$ & $84.9(5.1)$ & $74.9(9.8)$ & ${ }^{\mathrm{c}} 0.001^{* *}$ \\
\hline Mental health & $60.6(2.7)$ & $67.4(3.0)$ & $77.2(3.2)$ & $75.2(3.4)$ & ${ }^{\mathrm{c}} 0.37$ \\
\hline
\end{tabular}

BMI: body mass index; BDI-II: Beck Depression Inventory; CCI: Charlson Comorbidity Index; IPAQ: International Physical Activity Questionnaire; SF-36: Short-Form Health Survey. ${ }^{\mathrm{a}} \chi^{2}$ - square test, ${ }^{\mathrm{b}}$ Students $t$ test; ${ }^{\mathrm{c}}$ Kruskal-Wallis. ${ }^{*} \mathrm{P}<0.05$; ${ }^{* \star} \mathrm{P}<0.01$.

Table 3. Stepwise multiple regression analysis for predictors of physical activity (International Physical Activity Questionnaire - IPAQ)

\begin{tabular}{|c|c|c|c|c|c|}
\hline \multirow{2}{*}{ Dependent variables } & \multirow{2}{*}{ Stand B of coefficient } & \multirow{2}{*}{$\mathbf{t}$} & \multirow{2}{*}{$P$ value } & \multicolumn{2}{|c|}{ 95\% Confidence interval } \\
\hline & & & & Lower limit & Upper limit \\
\hline \multicolumn{6}{|l|}{ Gender } \\
\hline \multicolumn{6}{|l|}{ BMl } \\
\hline Age (y) & .008 & .62 & .53 & -.016 & .032 \\
\hline BDI-II scores & .005 & .43 & .66 & -.017 & .027 \\
\hline $\mathrm{CCl}$ & .008 & .16 & .87 & -.089 & .104 \\
\hline \multicolumn{6}{|l|}{ SF-36 subscales } \\
\hline Functional capacity & .008 & 2.88 & $.004^{\star \star}$ & .003 & .014 \\
\hline Physical limitation & .000 & .15 & .88 & -.003 & .004 \\
\hline Pain & -.001 & -.37 & .71 & -.006 & .004 \\
\hline General state of health & .005 & 1.54 & .12 & -.001 & .012 \\
\hline Vitality & -.001 & -.17 & .86 & -.009 & .007 \\
\hline Social aspects & -.001 & -.26 & .79 & -.006 & .005 \\
\hline Emotional limitation & .000 & .23 & .82 & -.004 & .005 \\
\hline \multicolumn{6}{|l|}{ Final model } \\
\hline Functional capacity & .269 & 3.843 & 0.000 & 0.004 & 0.12 \\
\hline
\end{tabular}

BMI: body mass index; BDI-II: Beck Depression Inventory; SF-36: Short-Form Health Survey; CCl: Charlson Comorbidity Index.

** $p<0.01$ 
exercise could be more efficacious. A previous study has shown that the presence of multiple comorbid illnesses or functional impairments is a more important predictor of limited life expectancy in older diabetic patients (2). Corroborating this report, we suggest that sedentary life is a vital link to be modified in this unwanted chain of events.

Our data showed that a significant proportion of diabetic patients, nearly $50 \%$, have a sedentary lifestyle. Of interest, diabetic patients revealed to be more active than an age-matched control population, which is probably the result of education: this indicates a need for more educational campaigns among the general population. These findings are in agreement with others studies showing lack of exercise and consequent obesity in the world population (38). Other studies have confirmed high prevalence of physical inactivity in diabetic individuals, mainly among females $(23,39)$.

The diabetic population and the subsequent control group investigated in the DPAF study was formed mostly by adults and elderly patients. In agreement with most diabetes reports, patient aged are above 40 years (3). The distribution was nearly homogeneous when evaluated by sex, with no statistical differences between groups, only a modest increase in the number T2DM females. The higher number of female patients found in this study could be justified by a greater demand and increased use of public health services by women (40). The diabetic population of the DPAF study showed $64.5 \%$ of excessive weight (overweight/mildly obesity), $19.5 \%$ of moderate/severe obesity, and only $15.5 \%$ of healthy weight. In the control group, $70 \%$ had excessive weight (overweight/mildly obese), 12\% moderate/severe obesity, and only $18 \%$ had ideal weight. All this confirms the urgency for wide and specific measures to be taken, possibly, by a multidisciplinary team in the health system. Physical inactivity (PI) and smoking have been considered risk factors for early mortality. Sedentary lifestyle and smoking have been considered risk factors for early mortality (41). In this study, a small percentage of the population investigated smoked, $6 \%$ of patients versus $8 \%$ of the control subjects. Heavy drinking was identified in $30 \%$ of controls, while only in $10 \%$ of diabetic patients. Again, this points out to the need to enlighten the general population about the hazards of heavy drinking in order to avoid preventable diseases.

Some limitations must be presently acknowledged. The study involved a small number of control subjects and this was partially due to the necessity of exclud- ing age-related subjects presenting comorbidities. First, this is a cross-sectional evaluation, and future research on this subject, particularly prospective studies, could evaluate the effects of modifying patient dependence on adherence to a physical activity program. Adherence to diabetes treatment is the key strategy to achieve adequate glycemic control.

In summary, our data show that functional capacity is independently related to physical activity in diabetic patients. Also, individuals with a sedentary lifestyle have more depressive symptoms. Based on these findings, future prospective studies should examine the relationship between patient independence and the level of physical activity. Also, depression treatment can contribute to improve adherence to physical activity.

\section{REFERENCES}

1. Jafar TH, Chaturvedi N, Pappas G. Prevalence of overweight and obesity and their association with hypertension and diabetes mellitus in an Indo-Asian population. CMAJ. 2006;175:1071-7.

2. Huang ES, Zhang $\mathrm{Q}$, Gandra N, Chin MH, Meltzer DO. The effect of comorbid illness and functional status on the expected benefits of intensive glucose control in older patients with type 2 diabetes: a decision analysis. Ann Intern Med. 2008;149:11-9.

3. King H, Aubert RE, Herman WH. Global burden of diabetes, 19952025: prevalence, numerical estimates, and projections. Diabetes Care. 1998;21:1414-31.

4. Crawford AG, Cote C, Couto J, Daskiran M, Gunnarsson C, Haas $\mathrm{K}$, et al. Prevalence of obesity, type II diabetes mellitus, hyperlipidemia, and hypertension in the United States: findings from the GE Centricity Electronic Medical Record database. Popul Health Manag. 2010;13:151-61.

5. Ryan AS. Exercise in aging: its important role in mortality, obesity and insulin resistance. Aging Health. 2010;6:551-63.

6. Tuomilehto HP, Seppa JM, Partinen MM, Peltonen M, Gylling H, Tuomilehto JO, et al. Lifestyle intervention with weight reduction: first-line treatment in mild obstructive sleep apnea. Am J Respir Crit Care Med. 2009;179:320-7.

7. Knowler WC, Barrett-Connor E, Fowler SE, Hamman RF, Lachin JM, Walker EA, et al. Reduction in the incidence of type 2 diabetes with lifestyle intervention or metformin. $\mathrm{N}$ Engl J Med. 2002;346:393-403.

8. Campbell HM, Khan N, Cone C, Raisch DW. Relationship between diet, exercise habits, and health status among patients with diabetes. Res Social Adm Pharm. 2011;7:151-61.

9. Archer T, Fredriksson A, Schutz E, Kostrzewa RM. Influence of physical exercise on neuroimmunological functioning and health: aging and stress. Neurotox Res. 2011;20:69-83.

10. Tamari K. Baseline comorbidity associated with the short-term effects of exercise intervention on quality of life in the Japanese older population: an observational study. Arch Phys Med Rehabil. 2010;91:1363-9.

11. Delahanty LM, Conroy MB, Nathan DM. Psychological predictors of physical activity in the diabetes prevention program. J Am Diet Assoc. 2006;106:698-705.

12. Penn L, White M, Oldroyd J, Walker M, Alberti KG, Mathers JC. Prevention of type 2 diabetes in adults with impaired glucose 
tolerance: the European Diabetes Prevention RCT in Newcastle upon Tyne, UK. BMC Public Health. 2009;9:342.

13. Kolt GS, Schofield GM, Kerse N, Garrett N, Schluter PJ, Ashton T, et al. The Healthy Steps Study: a randomized controlled trial of a pedometer-based Green Prescription for older adults. Trial protocol. BMC Public Health 2009;9.

14. Arora E, Shenoy S, Sandhu JS. Effects of resistance training on metabolic profile of adults with type 2 diabetes. Indian $\mathrm{J}$ Med Res. 2009;129:515-9.

15. Winnick JJ, Sherman WM, Habash DL, Stout MB, Failla ML, Belury MA, et al. Short-term aerobic exercise training in obese humans with type 2 diabetes mellitus improves whole-body insulin sensitivity through gains in peripheral, not hepatic insulin sensitivity. J Clin Endocrinol Metab. 2008;93:771-8.

16. Praet SF, van Rooij ES, Wijtvliet A, Boonman-de Winter LJ, Enneking $\mathrm{T}$, Kuipers $\mathrm{H}$, et al. Brisk walking compared with an individualised medical fitness programme for patients with type 2 diabetes: a randomised controlled trial. Diabetologia. 2008;51:736-46.

17. Atkinson G, Davenne D. Relationships between sleep, physical activity and human health. Physiol Behav. 2007;90:229-35.

18. Van Rooijen AJ, Rheeder P, Eales CJ, Becker PJ. Effect of exercise versus relaxation on haemoglobin A1C in Black females with type 2 diabetes mellitus. QJM. 2004;97:343-51.

19. Smith DW, McFall SL. The relationship of diet and exercise for weight control and the quality of life gap associated with diabetes. J Psychosom Res. 2005;59:385-92.

20. McKay HG, King D, Eakin EG, Seeley JR, Glasgow RE. The diabetes network internet-based physical activity intervention: a randomized pilot study. Diabetes Care. 2001;24:1328-34.

21. Lazarevic G, Antic S, CvetkovicT, Vlahovic P,Tasic I, Stefanovic V. A physical activity programme and its effects on insulin resistance and oxidative defense in obese male patients with type 2 diabetes mellitus. Diabetes Metab. 2006;32:583-90.

22. Sridhar G, Putcha V. Sleep and body weight in diabetes mellitus: a large retrospective analysis from South India. Diabetes Res Clin Pract. 2006:209-11.

23. Morrato EH, Hill JO, Wyatt HR, Ghushchyan V, Sullivan PW. Physical activity in U.S. adults with diabetes and at risk for developing diabetes, 2003. Diabetes Care. 2007;30:203-9.

24. De Greef K, Deforche B, Tudor-Locke C, De Bourdeaudhuij I. A cognitive-behavioural pedometer-based group intervention on physical activity and sedentary behaviour in individuals with type 2 diabetes. Health Educ Res. 2010;25:724-36.

25. Negri C, Bacchi E, Morgante S, Soave D, Marques A, Menghini E, et al. Supervised walking groups to increase physical activity in type 2 diabetic patients. Diabetes Care. 2010;33:2333-5.
26. Hamdy O, Goodyear LJ, Horton ES. Diet and exercise in type 2 diabetes mellitus. Endocrinol Metab Clin North Am. 2001;30:883907.

27. Tuttolomondo A, Placa SL, Raimondo DD, Bellia C, Caruso A, Lo Sasso B, et al. Adiponectin, resistin and IL-6 plasma levels in subjects with diabetic foot and possible correlations with clinical variables and cardiovascular co-morbidity. Cardiovasc Diabetol. 2010;9:50.

28. Plotnikoff RC, Taylor LM, Wilson PM, Courneya KS, Sigal RJ, Birkett N, et al. Factors associated with physical activity in Canadian adults with diabetes. Med Sci Sports Exerc. 2006;38:1526-34.

29. American Diabetes Association. Diagnosis and classification of diabetes mellitus. Diabetes Care. 2011;34 Suppl 1:S62-9.

30. Bassett DR Jr. International physical activity questionnaire: 12-country reliability and validity. Med Sci Sports Exerc. 2003;35:1396.

31. Hallal PC, Gomez LF, Parra DC, Lobelo F, Mosquera J, Florindo AA, et al. Lessons learned after 10 years of IPAQ use in Brazil and Colombia. J Phys Act Health. 2010;7 Suppl 2:S259-64.

32. Ware JE Jr. SF-36 health survey update. Spine (Phila Pa 1976). 2000;25:3130-9.

33. Laguardia J, Campos MR, Travassos CM, Najar AL, Anjos LA, Vasconcellos MM. Psychometric evaluation of the SF-36 (v.2) questionnaire in a probability sample of Brazilian households: results of the survey Pesquisa Dimensões Sociais das Desigualdades (PDSD), Brazil, 2008. Health Qual Life Outcomes. 2011;9:61.

34. Charlson ME, Pompei P, Ales KL, MacKenzie CR. A new method of classifying prognostic comorbidity in longitudinal studies: development and validation. J Chronic Dis. 1987;40:373-83.

35. Martins M, Blais R. Evaluation of comorbidity indices for inpatient mortality prediction models. J Clin Epidemiol. 2006;59:665-9.

36. Beck AT, Steer RA. Internal consistencies of the original and revised Beck Depression Inventory. J Clin Psychol. 1984;40:1365-7.

37. Gorenstein C, Andrade L, Vieira Filho AH, Tung TC, Artes R. Psychometric properties of the Portuguese version of the Beck Depression Inventory on Brazilian college students. J Clin Psychol. 1999;55:553-62.

38. Obesity: preventing and managing the global epidemic. World Health Organ Tech Rep Ser. 2000;894:i-xii, 1-253.

39. Lin EH, Katon W, Von Korff M, Rutter C, Simon GE, Oliver M, et al. Relationship of depression and diabetes self-care, medication adherence, and preventive care. Diabetes Care. 2004;27:2154-60.

40. Goldenberg P, Schenkman S, Franco LJ. Prevalência de diabetes mellitus: diferenças de gênero e igualdade entre os sexos. Rev Bras Epidemiol. 2003;6:18-28.

41. Peeters A, Barendregt JJ, Willekens F, Mackenbach JP, AI Mamun A, Bonneux L. Obesity in adulthood and its consequences for life expectancy: a life-table analysis. Ann Intern Med. 2003;138:24-32. 